\title{
Autosomal dominant congenital benign spinal muscular atrophy
}

INSERM

\section{Source}

INSERM. (1999). Orphanet: an online rare disease and orphan drug data base. Autosomal dominant congenital benign spinal muscular atrophy. ORPHA:1216

Autosomal dominant congenital benign spinal muscular atrophy is a rare distal hereditary motor neuropathy, with a variable clinical phenotype, typically characterized by congenital, non-progressive, predominantly distal, lower limb muscle weakness and atrophy and cong enital (or early-onset) flexion contractures of the hip, knee and ankle joints. Reduced or absent lower limb deep tendon reflexes, skeletal anomalies (bilateral talipes equinovarus, scoliosis, kyphoscoliosis, lumbar hyperlordisis), late ambulation, waddling gait, joint hyperlaxity and/or bladder and bowel dysfuntion are usually also associated. 